\title{
The Retrospective Analysis of the 1964 Sheveluch Volcano Eruption (Kamchatka) Using the VolSatView Information System
}

\author{
Olga A. Girina ${ }^{1}$, Sergey I. Malkovsky ${ }^{2}$, Alexey A. Sorokin ${ }^{2}$, Evgeny A. Loupian ${ }^{3}$ \\ ${ }^{1}$ Institute of Volcanology and Seismology FEB RAS, Petropavlovsk-Kamchatsky, Russia \\ girina@kscnet.ru \\ ${ }^{2}$ Computing Center FEB RAS, Khabarovsk, Russia \\ ${ }^{3}$ Space Research Institute RAS, Moscow, Russia
}

Owing to modern development of information technologies and computer simulation systems, and datasets derived from open historical meteorological data archives, it appeared possible to perform retrospective analysis of large explosive volcanic eruptions. This work analyzes the results of simulation of the events associated with the eruptive cloud propagation during the catastrophic eruption of the November, 1964 Sheveluch volcano. The obtained additional eruptive cloud parameters enabled us to reproduce the dynamics of the explosive eruption and to validate its magmatic genesis.

Keywords: Kamchatka, volcano Sheveluch, catastrophic eruption, eruptive cloud, PUFF, VolSatView 


\title{
РЕТРОСПЕКТИВНЫЙ АНАЛИЗ ИЗВЕРЖЕНИЯ 1964 Г. ВУЛКАНА ШИВЕЛУЧ (КАМЧАТКА) С ПОМОЩЬЮ ИНФОРМАЦИОННОЙ СИСТЕМЫ VOLSATVIEW
}

\author{
О.А. Гирина ${ }^{1}$, С.И. Мальковский', А.А. Сорокин ${ }^{2}$, Е.А. Лупян \\ ${ }^{1}$ Институт вулканологии и сейсмологии ДВО РАН, Петропавловск-Камчатский, Россия \\ girina@kscnet.ru \\ ${ }^{2}$ Вычислительный центр ДВО РАН, Хабаровск, Россия \\ ${ }^{3}$ Институт космических исследований РАН, Москва, Россия
}

Современное развитие информационных технологий и систем компьютерного моделирования природных процессов, а также появление в открытом доступе исторических архивов метеорологических данных, позволяют проводить ретроспективный анализ крупных эксплозивных извержений вулканов. Эта работа посвящена моделированию и анализу событий, связанных с распространением эруптивных облаков во время катастрофического извержения вулкана Шивелуч в ноябре 1964 г. Полученные дополнительные параметры эруптивных облаков позволили восстановить динамику эксплозивного извержения.

Ключевые слова: Камчатка, вулкан Шивелуч, катастрофическое извержение, эруптивное облако, PUFF, VolSatView

\section{Введение}

Вулкан Молодой Шивелуч (56³8'10" с.ш. 161²18'54" в.д., абс. высота 2500 м) относится к Северной группе вулканов Камчатки, расположен в 50 км от п. Ключи на левом берегу р. Камчатка в и 450 км от г. Петропавловск-Камчатский. Это самый северный действующий вулкан Камчатки (рис. 1).

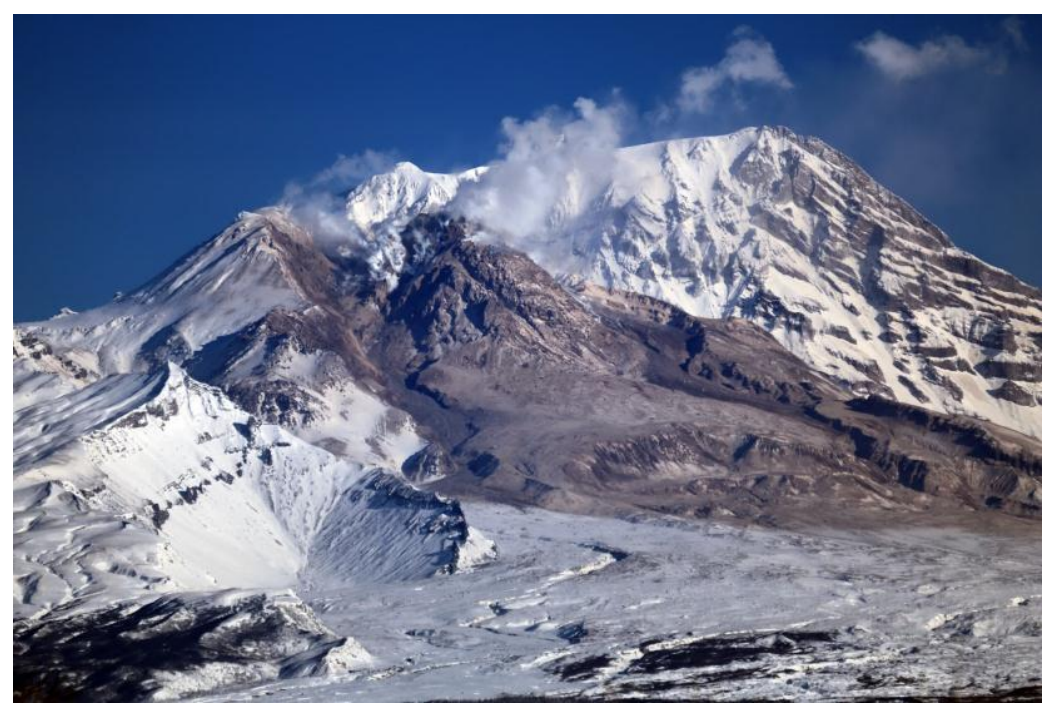


Молодой Шивелуч (далее Шивелуч) располагается на дне древней кальдеры, ближе к ее северо-западному краю. Он образован множеством слившихся между собой андезитовых экструзивных куполов, их агломератовых мантий и коротких лавовых потоков. Поперечник основания его постройки - 6х7 км. До извержения 1964 г. четыре купола (Центральный, Суелич и др.) находились в привершинной части вулкана.

Для вулкана известны два типа исторических извержений: 1) катастрофические эксплозивные типа направленных взрывов с выносом эруптивных продуктов до 2-2,5 км³ (1854 и 1964 гг.); 2) умеренные по силе экструзивно-эксплозивно-эффузивные, связанные с ростом экструзивных куполов (1790-1810 гг., 1879-1883 гг., 1896-1897 гг., 1925-1930 гг., 1944-1950 гг., 1980 г. - наст. вр.), сопровождаемые пароксизмальными эксплозивными событиями с объемом изверженного материала до $0,5 \mathrm{~km}^{3}$ [2], [3], [8], [9] и др. Состав пород вулкана преимущественно от андезитов до дацитов.

\section{Извержение вулкана в 1964 г.}

Катастрофическое извержение вулкана Шивелуч началось 11 ноября 1964 г. в 19:07 GMT и продолжалось 1 ч 15 мин [3]. В результате извержения на месте группы экструзивных куполов вулкана образовался двойной эксплозивный кратер размером 1,5х3,0 км, открытый на юг: северная его часть овальной формы размером 1,5х1,0 км, южная - трапециевидной формы размером 2,0х2,0 км. В отложениях у нижней границы кратера образовалось несколько ступеней, наибольшая из которых была высотой до 100 м. Общий объем изверженного и перемещенного материала (образования агломерата направленного взрыва, пирокластических потоков, тефры) составил 2,3 км ${ }^{3}[3]$.

Хотя извержение вулкана происходило ранним ноябрьским утром до рассвета, многие наблюдатели отмечали, что в 19:15 GMT в левой стороне кратера вулкана «пробивался узкий столб пламени с небольшим отблеском по кратеру направо» [10, стр. 29], а над вулканом уже поднялась до 12-15 км над уровнем моря (н.у.м.) огромная пепловая туча, в которой сверкали широкие молнии, но верхняя ее часть была белой. Белое клубящееся облако над Шивелучем было отмечено в 19:05 GMT из п. Усть-Камчатск [10].

На всем интервале высот от 300 до 15000 м дул устойчивый ветер западного и северозападного направления [5], поэтому туча стала перемещаться на восток и юго-восток от вулкана.

B 20:20 GMT 11 ноября в п. Усть-Камчатск начался пеплопад - на поверхность земли из тучи выпадал крупный вулканический песок. В 20:30 GMT пеплопад усилился, в 22:00 GMT крупный вулканический песок сменился вулканической пылью [10]. Пеплопад продолжался в течение 3 ч, пепел отложился слоем 3 см, его количество составило 28 кг/м² [3]. К 01:00 GMT 12 ноября эруптивная туча надвинулась на Командорские острова, в п. Никольское пеплопад продолжался до 05:30 GMT (4,5 ч). Пепел отложился слоем 0,25 см, его количество составило 2 кг/м². Общая площадь территории суши и моря, покрытой пеплом, превышала 100 тыс. км² [3].

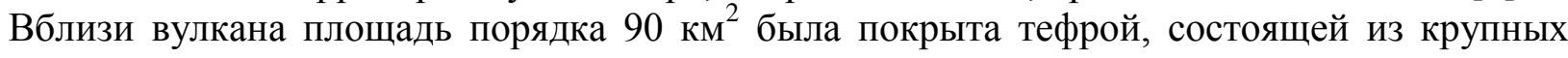
обломков пемзовидного андезита; в 30-40 км от вулкана тефра представлена крупным вулканическим песком с небольшим количеством пемзовых лапилли. Общий объем тефры определен в $0,3 \mathrm{\kappa м}^{3}[3]$.

\section{Методы восстановления извержения 1964 г. вулкана Шивелуч}

Компьютерное моделирование распространения эруптивной тучи, образовавшейся во время извержения Шивелуча 11 ноября 1964 г., выполнялось с помощью модели PUFF [12] и еe программной реализации Puff-UAF [11], которая была модифицирована сотрудниками Вычислительного центра Дальневосточного отделения (ВЦ ДВО) РАН [7]. Параметры для модели PUFF были подобраны максимально близко к известным параметрам эруптивной тучи извержения: модель источника - линейный над центром вулкана; минимальная высота подъема 
пеплового облака - 2500 м; максимальная его высота - 15000 м; распределение частиц пепла по высоте - Пуассона с максимальной концентрацией массы пепла в верхних пяти километрах облака. В модельном облаке преобладали частицы размером порядка 100 мкм, их распределение - нормальное; коэффициент горизонтальной диффузии - $10000 \mathrm{~m}^{2} / \mathrm{c}$; коэффициент вертикальной диффузии - $50 \mathrm{~m}^{2} / \mathrm{c}$; длительность моделирования - 12 ч, шаг сохранения результатов - 15 мин. Число модельных частиц составляло 15000 (визуализация пепла во взвешенном состоянии в атмосфере).

Метеорологические данные для моделирования были взяты из архива проекта реанализа ERA-40 Европейского центра среднесрочных прогнозов погоды (ECMWF - European Centre for Medium-Range Weather Forecasts) [14], содержащего ряды метеорологических полей с сентября 1957 г. по август 2002 г. Эти данные имеют глобальное покрытие с пространственным разрешением в $1,125^{\circ} \times 1,125^{\circ}$ и 23 уровнями давления $(1000,925,850,775,700,600,500,400$, $300,250,200,150,100,70,50,30,20,10,7,5,3,2,1$ мбар); шаг по времени составляет 6 ч. В расчетах использовались метеорологические поля зональной и меридиональной составляющих ветра, а также поля температуры, относящиеся к указанным выше уровням давления, на 18:00 GMT 11 ноября 1964 г. и 00:00, 06:00 и 12:00 GMT 12 ноября 1964 г.

Опорными точками для оценки параметров модельной эруптивной тучи были взяты координаты п. Усть-Камчатск (Камчатка) и п. Никольское (о. Беринга, Командоры).

\section{Результаты моделирования распространения эруптивной тучи 1964 г.}

Анализ результатов проведенного моделирования распространения эруптивной тучи во время извержения Шивелуча 11 ноября 1964 г., показал следующее:

1) начало пеплопада в п. Усть-Камчатск в 20:20 GMT 11 ноября практически совпадает с началом (20:22 GMT) прохождения над поселком модельного облака пепловых частиц на высоте до 8-11 км н.у.м. (рис. 2а); время окончания пеплопада в п. Усть-Камчатск (длительность пеплопада 3 ч) по опубликованным и модельным (23:22 GMT 11 ноября) данным также примерно совпадают (рис. 2б);

2) начало пеплопада в п. Никольское (о. Беринга) было отмечено в 01:20 GMT 12 ноября [10], оно близко с моментом времени, полученным при моделировании - 01:22 GMT (рис. 3a); времена окончания пеплопада в п. Никольское по опубликованным и модельным данным также совпадают - 05:30 и 05:37 GMT, соответственно (рис. 3б).

Реанализ событий извержения Шивелуча в 1964 г. с использованием метеорологических данных за 1964 г., а также проверенной на многих извержениях вулканов в течение многих лет модели PUFF, позволил получить хорошее совпадение наблюдаемых и модельных временных характеристик движения эруптивной тучи вулкана.

\section{Результаты моделирования эруптивной тучи 1964 г. в VolSatView}

Визуализация результатов моделирования эруптивной тучи 1964 г. была выполнена в информационной системе VolSatView [4], что позволило определить дополнительные характеристики пепловых облаков этого извержения, в частности:

- подьем пепловой тучи 11 ноября к 20:52 GMS до 17 км н.у.м. и к 22:37 GMS до 18 км н.у.м.; 12 ноября к 02:37 GMS - до 19 км н.у.м. и к 06:52 GMS - до 20 км н.у.м.;

- разделение эруптивной тучи на две и перемещение ее частей по разным траекториям от вулкана: нижней части (< 1.5-6.0 км н.у.м.) преимущественно на юго-восток и далее на восток, с изменением азимута от $108^{\circ}$ до $90^{\circ}$; верхней части (10.5-20 км н.у.м.) преимущественно на восток, с изменением азимута от $95^{\circ}$ до $87^{\circ}$ (рис. 4);

- средняя скорость распространения нижней части эруптивной тучи оценивается как 70 км/ч; верхней части тучи - 96 км/ч;

- выпадение пепла в п. Усть-Камчатск происходило из всей эруптивной тучи, в п. Никольское из ее нижней части (рис. 2, 3); 
- общая площадь территории, подвергшейся пеплопадам на суше и на море с 19:07 GMS 11

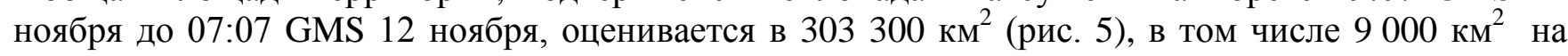
суше (на Камчатке и о-вах Беринга и Медном).
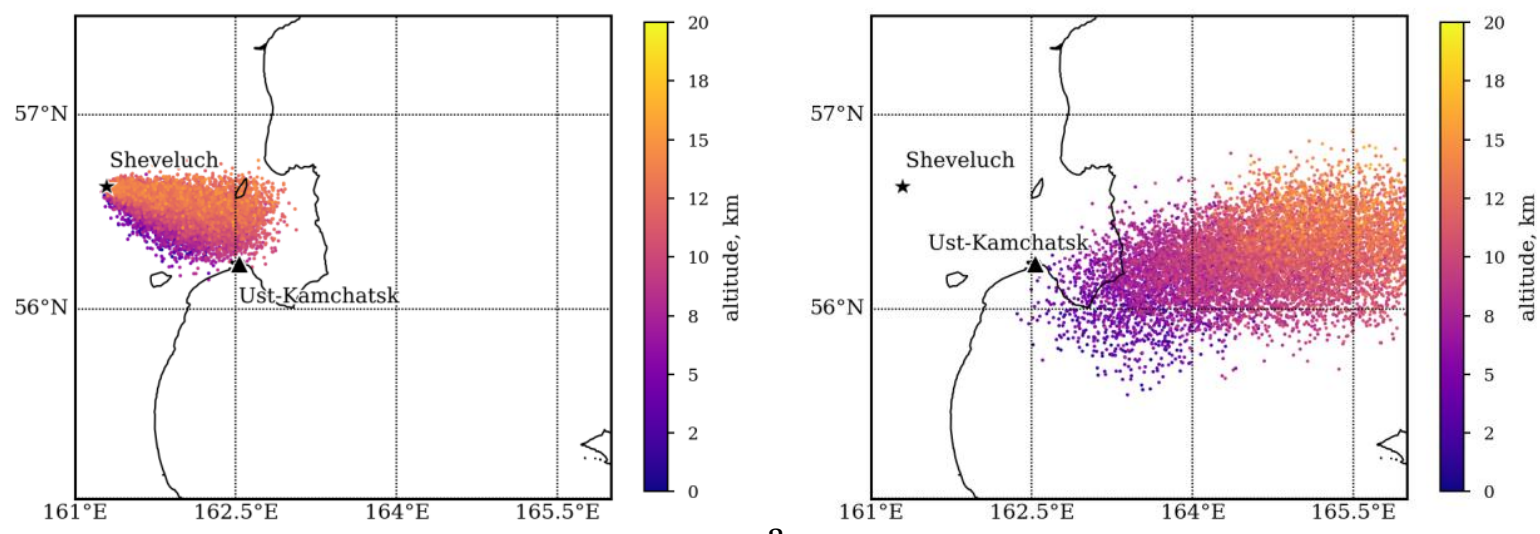

б Puc. 2.

Состояние эруптивной тучи влк. Шивелуч 11 ноября 1964 г. в районе п. Усть-Камчатск: начало пеплопада в 20:22 GMT (а) окончание пеплопада в 23:22 GMT (б)

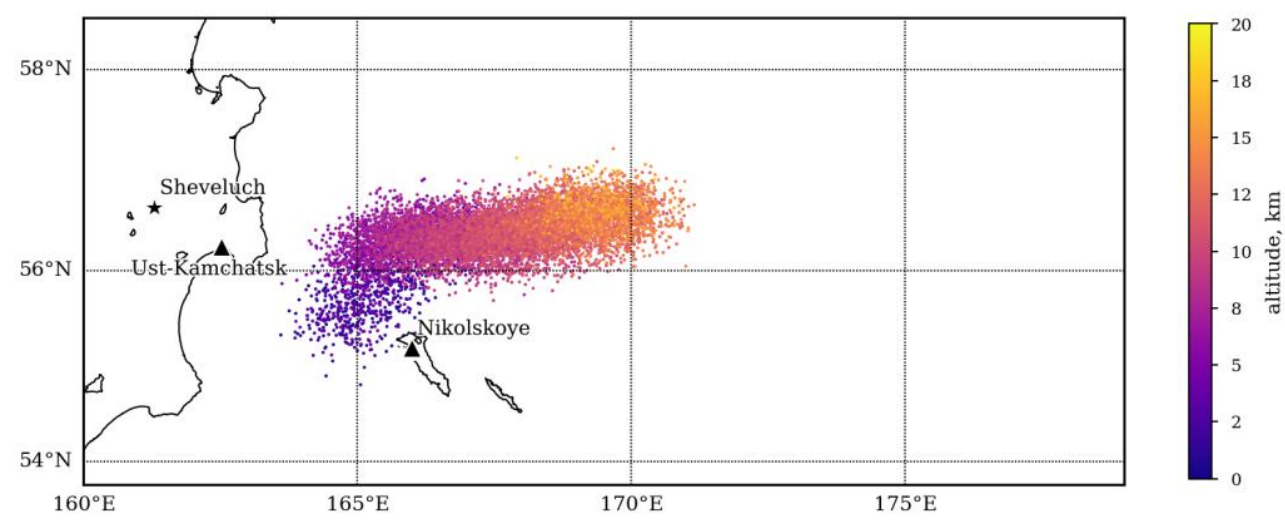

a

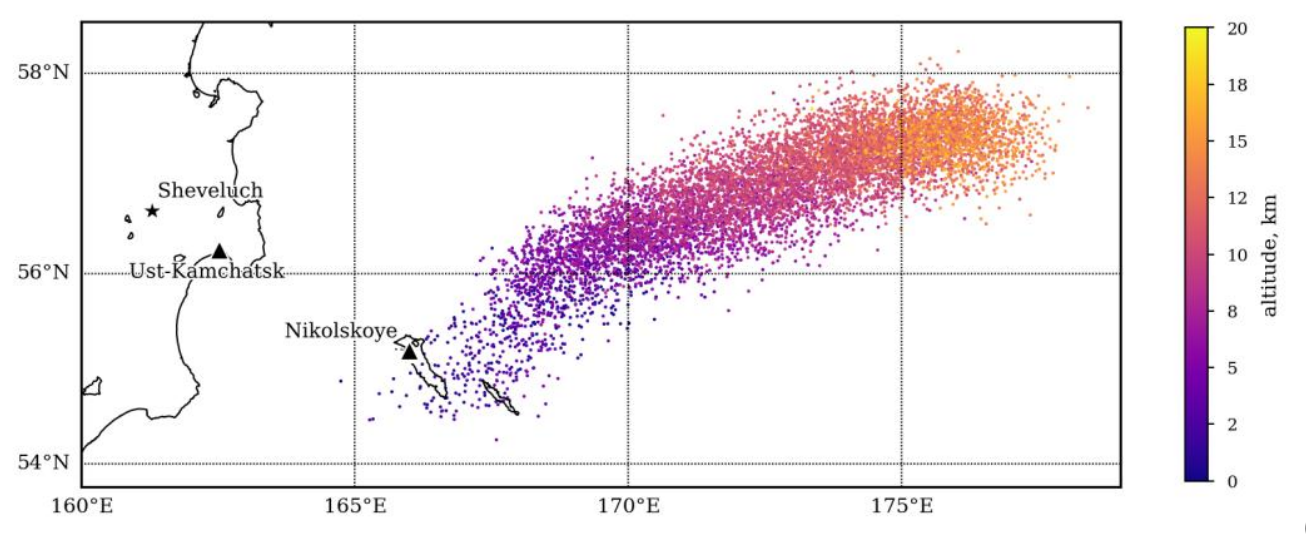

6

Рис. 3. Состояние эруптивной тучи влк. Шивелуч 12 ноября 1964 г. в районе п. Никольское (о. Беринга): начало пеплопада в 01:22 GMT (а) окончание пеплопада в 05:37 GMT (б)

\section{Обсуждение полученных результатов}

Результаты моделирования развития и распространения эруптивной тучи катастрофического извержения вулкана Шивелуч в 1964 г. подтвердили наблюденные во время извержения временные характеристики ее движения; кроме этого, позволили определить дополнительные ее параметры: изначальный подъем пеплового облака до 16 км н.у.м.; разделение эруптивной тучи на верхнюю и нижнюю части, перемещавшиеся по различным 
траекториям и с разной скоростью; подъем верхней части эруптивной тучи в течение 12 ч до 20 км н.у.м. Полученные характеристики эруптивной тучи дают возможность уточнить события эксплозивного извержения 1964 г.

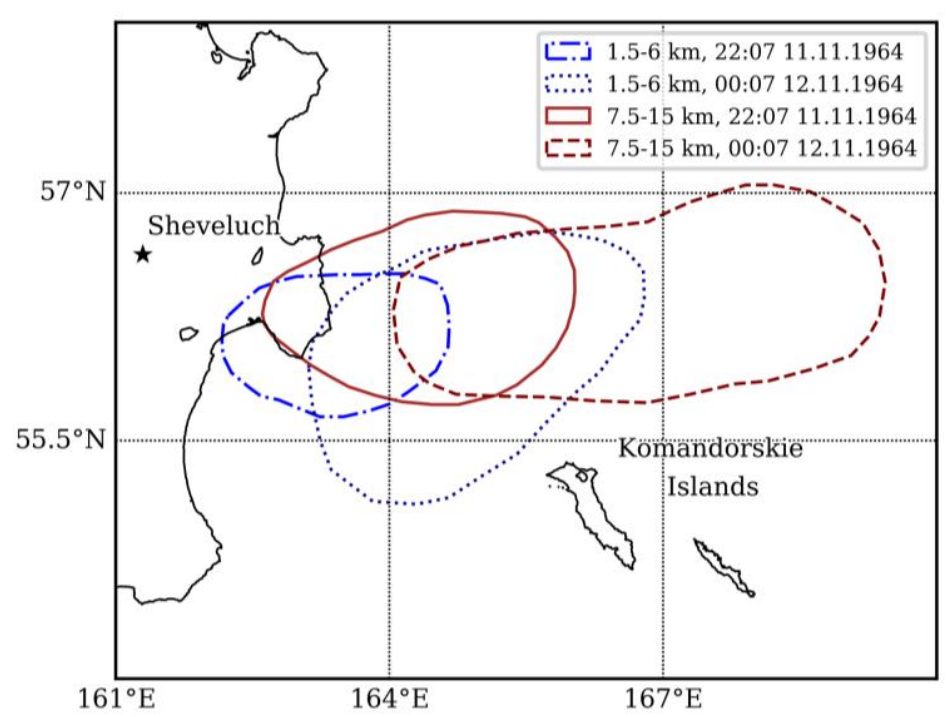

Рис. 4. Разделение эруптивной тучи на нижнюю и верхнюю и движение их по разным траекториям от влк. Шивелуч во время извержения 1964 г.

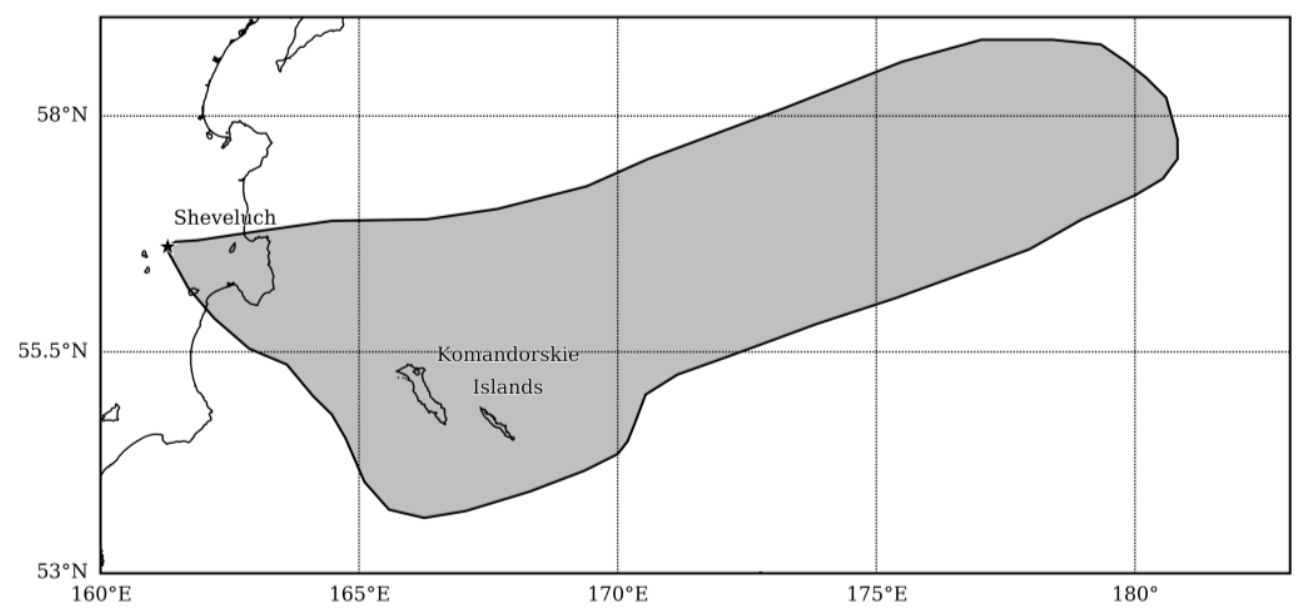

Рис. 5. Общая площзадь территории, подвергшейся пеплопадам с 19:07 GMS 11 ноября до 07:07 GMS 12 ноября во время извержения влк. Шивелуч в 1964 г.

В 19:07 GMT 11 ноября началось извержение вулкана: глубинное высокотемпературное вещество стало причиной событий, в результате которых в северной части кратера мощными направленными на юго-запад взрывами материал построек экструзивных куполов начал перемещаться на южный склон вулкана, формируя отложения агломерата направленного взрыва. Эруптивная колонна, несущая ювенильное высокотемпературное вещество, поднявшись из кратера вулкана до 16 км н.у.м., начала трансформироваться в облако, которое, прорезаемое многочисленными молниями, постепенно перемещалось на юго-восток (азимут $95^{\circ}$ ) от вулкана. Эруптивная колонна выносила на поверхность земли большие объемы свежего пирокластического материала, который в виде потоков отложился на продуктах направленного взрыва. Над движущимися образованиями направленного взрыва и пирокластических потоков клубились и смешивались пеплы, пески, пыль, мелкие обломки пород, нагруженная этим материалом туча поднималась до 6-10 км н.у.м., подпитывала главное эруптивное облако, но 
была слишком тяжелой и смещалась несколько южнее (азимут $108^{\circ}$ ), чем облако, в котором преобладал ювенильный материал.

Известно, что над Камчаткой проходит в среднем 70 циклонов в год, преимущественно они перемещаются от Японии по акватории Тихого океана на Алеутские острова или в Берингово море. Высота тропопаузы над Камчаткой в течение года варьируется в диапазоне 8-11 км н.у.м., суточная амплитуда ее колебаний составляет 60-100 м [4]. Исходя из этого, вполне логично, что главное эруптивное облако Шивелуча, высокоэнергетическое, как несущее глубинное высокотемпературное магматическое вещество (в отложениях тефры содержится 95 \% ювенильного вещества [1]), поднялось выше тропопаузы и двигалось с большей скоростью (96 км/ч), чем нижнее (70 км/ч); через 12 ч оно поднялось до 20 км н.у.м. То есть главной движущей силой событий 1964 г. было глубинное вещество, исходя из этого, генезис извержения вулкана магматическое эксплозивное извержение.

\section{Выводы}

Современные информационные технологии и системы, а также архивы инструментальных и справочных данных, позволяют проводить ретроспективный анализ крупных и катастрофических эксплозивных извержений вулканов. Достоверность получаемых модельных результатов дает возможность определять дополнительные характеристики эруптивных облаков таких извержений и восстанавливать их динамику.

Используя вышеуказанные средства и возможности, было проведено численное моделирование поведения эруптивной тучи во время извержения Шивелуча в 1964 г., восстановлено с течением времени ее развитие и распространение от вулкана, определены ее дополнительные характеристики. Полученные результаты моделирования эруптивной тучи Шивелуча позволили подтвердить генезис катастрофического извержения вулкана магматическое эксплозивное извержение.

\section{Благодарности}

Обработка данных производилась с использованием ресурсов Центров коллективного пользования “Центр данных ДВО РАН” (ВЦ ДВО РАН) [13] и “ИКИ-Мониторинг” (Институт космических исследований РАН) [6].

Работа выполнена при поддержке Российского научного фонда (проект № 16-17-00042)

\section{Referenses}

[1] Bogoyavlenskaya G.E., Braitseva O.A., Melekestsev I.V., Kirianov V.Yu., Dan Miller C. Catastrophic eruptions of the directed-blast type at Mount St. Helens, Bezymianny and Sheveluch volcanoes, J. of Geodynamic,1985, Vol. 3, No. 3-4, pp. 189-218. doi:10.1016/0264-3707(85)90035-3

[2] Girina O.A., Demyanchuk Yu.V., Melnikov D.V., Ushakov S.V., Ovsyannikov A.A., Sokorenko A.V. The Paroxysmal Phase of the February 27, 2005 Eruption on Young Sheveluch Volcano, Kamchatka. A Preliminary Report, Vulkanologiya i seismologiya, 2006, No. 1, pp. 16-23 (In Russian)

[3] Gorshkov G.S., Dubik Yu.M. Directed blast on Sheveluch volcano, In: Volcanoes and eruptions / G.S. Gorshkov - editor-in-chief, Moscow: Nauka, 1969, pp. 3-37 (In Russian)

[4] Gordeev E.I., Girina O.A., Lupyan E.A., Sorokin A.A., Kramareva L.S., Efremov V.Yu., Kashnitskiy A.V., Uvarov I.A., Burtsev M.A., Romanova I.M., MelnikovD.V., Manevich A.G., Korolev S.P., Verkhoturov A.L., The VolSatView information system for Monitoring the Volcanic Activity in Kamchatka and on the Kuril Islands, J. of Volcanol. Seismol., 2016, Vol. 10, No. 6, pp. 382-394, doi: 10.1134/S074204631606004X

[5] Kirianov V. Yu. Kamchatkan Volcanic Ashes as source of potential danger to passenger airlines, Vulkanologiya i seismologiya, 1992, No. 3, pp. 16-36 (In Russian)

[6] Loupian E. A., Proshin A. A., Burtsev M. A., Balashov I. V., Bartalev S. A., Efremov V. Yu., Kashnitskii A. V., Mazurov A. A., Matveev A.M., Sudneva O. A., Sychugov I. G., Tolpin V. A., Uvarov I. A. IKI center for collective use of satellite data archiving, processing and analysis systems aimed at solving the problems of 
environmental study and monitoring, Sovremennye problemy distantsionnogo zondirovaniya Zemli iz Kosmosa, 2015, Vol. 12, No. 5, pp. 263-284.

[7] Malkovsky S.I., Sorokin A.A., Korolev S.P. Improving the system of numerical simulation of volcanic ash propagation using the PUFF model, Russian J. of Earth Sciences, 2017, Vol. 17, No. 5, ES5003, pp. 1-6.

[8] Melekestsev I.V., Dvigalo V.N., Kirsanova T.P., Ponomareva V.V., Pevzner M.M. The 300 years of Kamchatka Volcanoes: the Young Sheveluch. An Analysis of the Dinamics and Impact of Eruptive Activity during the 17-20 ${ }^{\text {th }}$ Centuries. Part I. 1650-1964, Vulkanologiya i seismologiya, 2003, No. 5, pp. 3-19 (In Russian)

[9] Menyailov A.A. Sheveluch Volcano - Geological Structure, Composition and Eruptions. Moscow: Academy of Sciences USSR, 1955, 264 p. (In Russian)

[10] Piip B. I., Markhinin E. K. The Giant Eruption of Sheveluch Volcano on November 12, 1964 (preliminary report), Bull. Volcanol. Station, 1965, No. 39, pp. 28-34 (In Russian)

[11] Peterson R.A. Puff UAF User's Manual. 2003. Available at: http://web.archive.org/web/20121119195411/http://puff.images.alaska.edu/doc.shtml （accessed on 23.03.2016).

[12] Searcy C., Dean K., Stringer W. PUFF: a high-resolution volcanic ash tracking model, J. of Volcanol. Geotherm. Res., 1998, Vol. 80, No. 1/2, pp. 1-16.

[13] Sorokin A. A., Makogonov S. I., Korolev S. P. The Information Infrastructure for Collective Scientific Work in the Far East of Russia. Scientific and Technical Information Processing. 2017. Vol. 4, pp. 302-304.

[14] Uppala S. M., Kallberg P. W., Simmons A.J., Andrae U., Bechtold V. Da Costa, Fiorino M., Gibson J.K., Haseler J., Hernandez A., Kelly G.A., Li X., Onogi K., Saarinen S., Sokka N., Allan R.P., Andersson E., Arpe K., Balmaseda M.A., Beljaars A.C.M., Van De Berg L., Bidlot J., Bormann N., Caires S., Chevallier F., Dethof A., Dragosavac M., Fisher M., Fuentes M., Hagemann S., Holm E., Hoskins B.J., Isaksen L., Janssen P.A.E.M., Jenne R., McNally A.P., Mahfouf J.-F., Morcrette J.-J., Rayner N.A., Saunders R.W., Simon P., Sterl A., Trenberth K.E., Untch A., Vasiljevic D., Viterbo P., Woollen J. The Era-40 Re-analysis, Quarterly J. of Royal Meteor. Soc., 2005, Vol. 131, No. 612, pp. 2961-3012. doi: 10.1256/qj.04.176 